\title{
ANÁLISE DOS CONFLITOS DE USO DO SOLO NA MICROBACIA DO RIO GUAJIRU MEDIANTE TÉCNICAS DE PROCESSAMENTO DIGITAL DE IMAGENS SENTINEL-2
}

\begin{abstract}
Michele Barbosa Rocha
michelerochageo@gmail.com

Jairo Rodrigues Souza

https://doi.org/10.15628/geoconexoes.2019.9195

\section{RESUMO}

O proposito deste artigo foi apresentar os resultados da análise dos conflitos de uso do solo na microbacia do Rio Guajiru utilizando imagens Sentinel-2, dados de campo e o software ArcMap na versão 10.5. O rio Guajirú é o principal rio da margem direita da Lagoa de Extremoz, localizada na Bacia Hidrográfica do Rio Doce. Abrangendo os municípios de Ceará Mirim, São Gonçalo do Amarante e Ielmo Marinho, localizados no Estado do Rio Grande do Norte apresentando uma área de 21.502,704 hectares, equivalendo uma área de 215,027 $04 \mathrm{~km} 2$. Foi realizado o mapeamento das classes de uso do solo com auxilio do NDVI. Os resultados mostraram que a microbacia se encontra degradada devido o desmatamento para atividades agropastoris. Com base no mapa de uso e ocupação do solo na microbacia foi possível constatar que os campos antropizados ocupam $35,23 \%$ e as pastagens $18,88 \%$ ou seja maior parte da microbacia do Rio Guajiru se encontra entronizada.
\end{abstract}

Palavras-chave: Bacia hidrográfica. Sensoriamento remoto. Uso e ocupação do solo. Microbacia do rio Guajiru.

\section{ABSTRACT}

The purpose of this article the results of the analysis of land use conflicts in the Guajiru River watershed using Sentinel-2 images, field data and the ArcMap software in version 10.5. The Guajiru River is the main river on the right bank of the Lagoa de Extremoz, located in the Rio Doce River Basin. Covering the municipalities of CearáMirim, São Gonçalo do Amarante and lelmo Marinho, located in the State of Rio Grande do Norte presenting an area of 21,502,704 hectares, equivalent to an area of $215,02704 \mathrm{~km} 2$. The mapping of land use classes was carried out with the help of the NDVI. The results showed that the microbasin is degraded due to deforestation for agropastoral activities. Based on the map of land use and occupation in the microbasin, it was possible to verify that the anthropized fields occupy $35.23 \%$ and the pastures $18.88 \%$, or mostro of the Guajiru River watershed, are enthroned.

Keywords: Hydrographicbasin. Remotesensing. land use andoccupation. Watershed o the Guajiru River. 


\section{INTRODUÇÃO}

A microbacia hidrográfica do rio Guajiru, tributário da bacia hidrográfica do rio Doce localizado entre os municípios de Ceará Mirim, São Gonçalo do Amarante e lelmo Marinho, tem sofrido com constantes degradações ambientais decorridas, principalmente, pelas atividades agrícolas às margens do manancial como, por exemplo, feijão, milho e hortaliças, contribuindo com o seu assoreamento (ROCHA, 2016). Faustino (2014) comprovou que a respectiva bacia sofreu uma forte pressão imobiliária, culminando com a redução da cobertura vegetal e a ampliação das áreas de impermeabilização dos solos.

Estudos anteriores também revelaram os mesmos problemas. Chagas (1997), em seu estudo sobre o uso e ocupação do solo da bacia do Rio Doce, verificou que a mata ciliar foi gradativamente substituída pela horticultura e monocultura da cana-de-açúcar implantadas pelos moradores ribeirinhos. Lima (2005) também mostrou a presença de outro impasse: ausência de saneamento básico. 0 lançamento de esgotos clandestinos e as fossas sépticas locais culminaram no avanço da degradação ambiental do aqüífero e, consequentemente, o comprometimento da qualidade da água.

Marrafa (2017) defende a ideia da criação de uma unidade de conservação na bacia, afirmando que a mesma ainda apresenta qualidade e disponibilidade de recursos naturais. No entanto, o autor ressalta a importância da continuação de estudos mais aprofundados sobre o meio físico, biótico e socioeconômico regional.

Assim, do ponto de vista da gestão ambiental, a utilização da bacia hidrográfica como unidade de planejamento e gerenciamento ambiental não é recente (PIRES et al., 2008). Esta gestão pode ser gerida por um conjunto de órgãos e instituições com responsabilidades e funções, dentre as quais: coordenar, arbitrar os conflitos, implementar a política, planejar, regular, controlar o uso, preservar e recuperar os recursos hídricos e pela administração e aplicação no âmbito da bacia onde são arrecadados esses recursos (VITTE; GUERRA, 2004).

Entre as metodologias voltadas à gestão de bacias hidrográficas estão aquelas que empregam o uso de Sistemas de Informações Geográficas (SIGs) e análise de imagens orbitais através de técnicas de processamento digital de imagens em ambiente com a intenção de determinar medidas de manejo ambiental (PIRES et al., 2008).O levantamento da cobertura e do uso da terra constitui uma forma de fornecer subsídios para as análises e avaliações dos impactos ambientais como aqueles provenientes de desmatamentos, indicando a distribuição geográfica da tipologia da cobertura terrestre (IBGE, 2013).

Costa, Souza e Silva (2016) mostraram a relevância das ferramentas de geoprocessamento para análise multitemporal e na atualização dos limites da bacia hidrográfica do Rio Doce por meio de programas TauDEM, SAGA e TERRAHIDRO.O estudo se mostrou satisfatório uma vez que os autores chegaram à conclusão de que o TERRAHIDRO apresentou o melhor resultado para a delimitação da bacia, propondo-se seu uso embacias hidrográficas com escalas média e grande (COSTA; SOUZA; SILVA, 2016).

Atualmente, dentre as ferramentas mais empregadas nos estudos ambientais em bacias hidrográficas está o software ArcGIS 10.5, principalmente, devido a sua facilidade e precisão na 
obtenção dos resultados. Sedo assim, cabe ainda ressaltar que a bacia hidrográfica do Rio Doce é uma das fontes de abastecimento humano de parte do município de Natal e região metropolitana através da lagoa de Extremoz. Porém, ainda há poucos estudos sobre os tributários que integram esta bacia como, por exemplo, o rio Guajiru.

Deste modo, considerado a importância da microbacia como mantedora do ciclo hidrológico local se faz necessários estudos mais aprofundados sobre os tributários que integram a bacia hidrográfica do Rio Doce. Portanto, o presente estudo teve como objetivo analisar os conflitos de uso do solo na microbacia do Rio Guajiru mediante técnicas de geoprocessamento, empregando processamento digital de imagens Sentinel-2 e visitas in loco de campo.

Nesta perspectiva, acredita-se que o estudo contribuirá com o fornecimento de informações mais detalhada da área que envolve o tributário Guajiru, fortalecendo e subsidiando novos estudos sobre a bacia. Para atender o objetivo da pesquisa foi realizada a descrição das atividades desenvolvidas na microbacia estudada ao mesmo temo como o uso do solo de forma desordenada tem comprometido a qualidade ambiental dos mananciais existentes na área.

\section{MATERIAIS E MÉTODOS}

O recorte geográfico da área de estudo abrange os municípios de Ceará Mirim, São Gonçalo do Amarante e lelmo Marinho, localizados no Estado do Rio Grande do Norte apresentando uma área de 21.502,704 hectares, equivalendo uma área de 215,027 04 km2. Para chegar ao local de estudo, as principais vias de acesso se dão pela rodovia BR-101, no sentido zona norte de Natal-RN e, em seguida, pela BR-406 até o município de Ceará-Mirim. Logo após passar pelo Instituto Federal de Educação, Ciência e Tecnologia do Rio Grande do Norte (IFRN) Campus Ceará-Mirim, entra-se na rodovia RN-064 sentido lelmo Marinho (Figura 1).

Figura 1: Localização da área de estudo. A microbacia analisada está na cor vermelha.
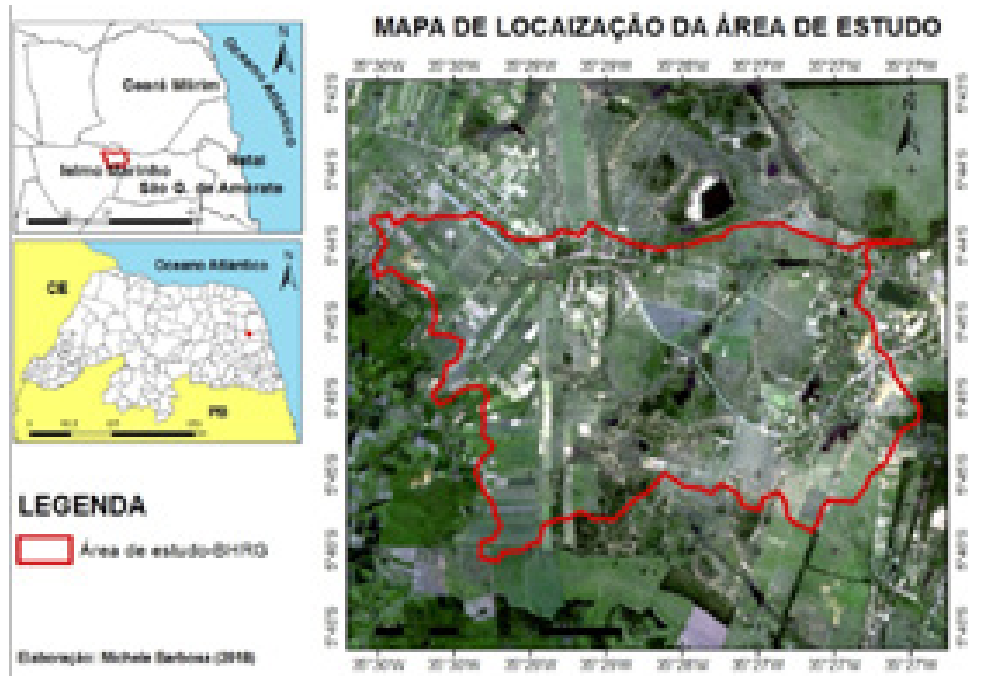

Fonte: Autoria própria (2018). 
O presente estudo foi dividido em três etapas metodológicas: pré-campo, campo e pós-campo, de acordo com a figura 2 .

Figura 2: Fluxograma mostrando as etapas metodológicas para desenvolvimento deste artigo.

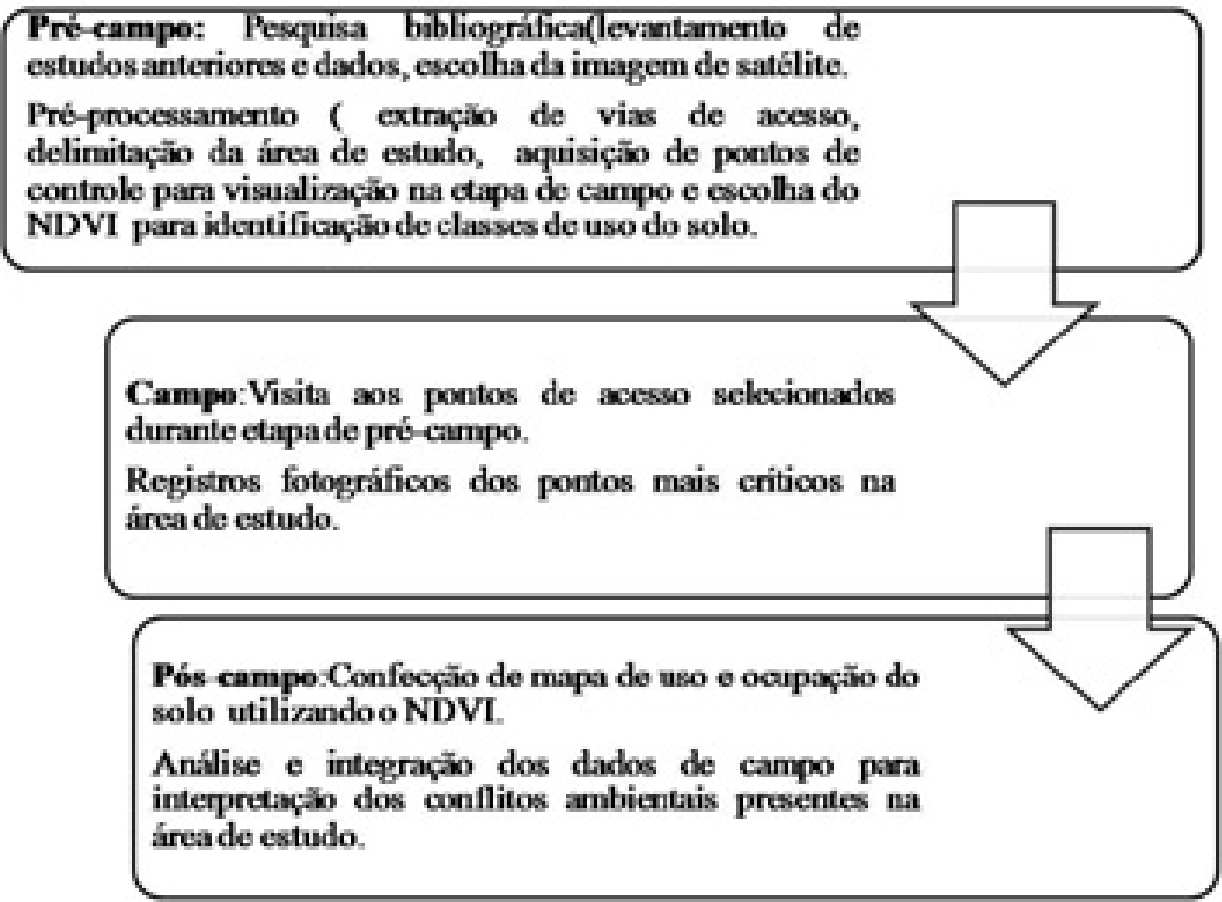

Fonte: Autoria própria (2018).

\section{ETAPA DE PRÉ-CAMPO}

$\mathrm{Na}$ etapa de pré-campo, foram realizadas pesquisas bibliográficas e construção de dados prévios, empregando-se, para tanto, técnicas de geoprocessamento no software ArcGISversão 10.5. A pesquisa bibliográfica consistiu no levantamento teórico do projeto, consultando periódicos sobre a bacia hidrográfica do rio Doce, microbacia do rio Guajiru e sítios eletrônicos de órgãos competentes como Instituto Brasileiro de Geografia e Estatística (IBGE), do Serviço Geológico Brasileiro (CPRM) e Instituto de Desenvolvimento Sustentável e Meio Ambiente (IDEMA).

Antes das atividades de geoprocessamento, foi realizado o download de imagens do sensor Sentinel-2 diretamente no site do Serviço Geológico Americano (USGS) de forma gratuita. As bandas espectrais do azul (B02), verde (B03), vermelho (B04) e infravermelho próximo (B08) apresentam resolução espacial e temporal de dez metros e dezesseis dias, sendo viáveis para averiguações de caráter ambiental.

Essas imagens baixadas em conjunto com o software Google Earth Pro, foram fundamentais para a delimitação e extração das vias de acesso. 0 geoprocessamento possibilitou a modelagem, importação, processamento e armazenamento de dados. Dentre os primeiros procedimentos, foi feita a importação da imagem Sentinel-2 para a delimitação da área de estudo (Figura 1). 
Com a composição de bandas espectrais 3R2G1B, possibilitou a visualização prévia dos elementos ambientais presentes na área de estudo, contribuindo para a vetorização (shapefiles de linha) dos acessos (estradas carroçáveis e rodovias estaduais) e marcação de vinte e três pontos de controle (bifurcação de estradas, rios, lagoas, comunidades e pedreiras) a fim da eficiência das atividades de campo. Por meio do algoritmo do Índice de Vegetação da Diferença Normalizada (NDVI), foi realizado a distribuição das classes de uso e cobertura do solo na microbacia do rio Guajiru. Este método consistiu em analisar a condição da vegetação natural ou agrícola nas imagens geradas por sensores remotos (BORATTO; GOMIDE, 2013) é frequentemente usado para medir a intensidade de atividade clorofiliana, inclusive comparando vários períodos distintos (RISSO et al., 2009).

0 cálculo do NDVI foi realizado a partir da diferença entre as refletâncias das bandas B04 (infravermelho próximo) e B03 (vermelho) dividido pela soma das refletâncias dessas duas respectivas bandas (ROUSE, 1973; ALLEN et al., 2002) (Figura 3). Como resultados, tem-se um conjunto de classes, variando de -1 a 1, de modo que quanto mais próximo do 1 maior indício de presença de vegetação, e quanto mais próximo do -1 maior indício de presença de solos descobertos ou água (PONZONI; SHIMABUKURO, 2007; POLONIO, 2015).

Figura 3: Cálculo do NDVI através do algoritmo "raster calculator".

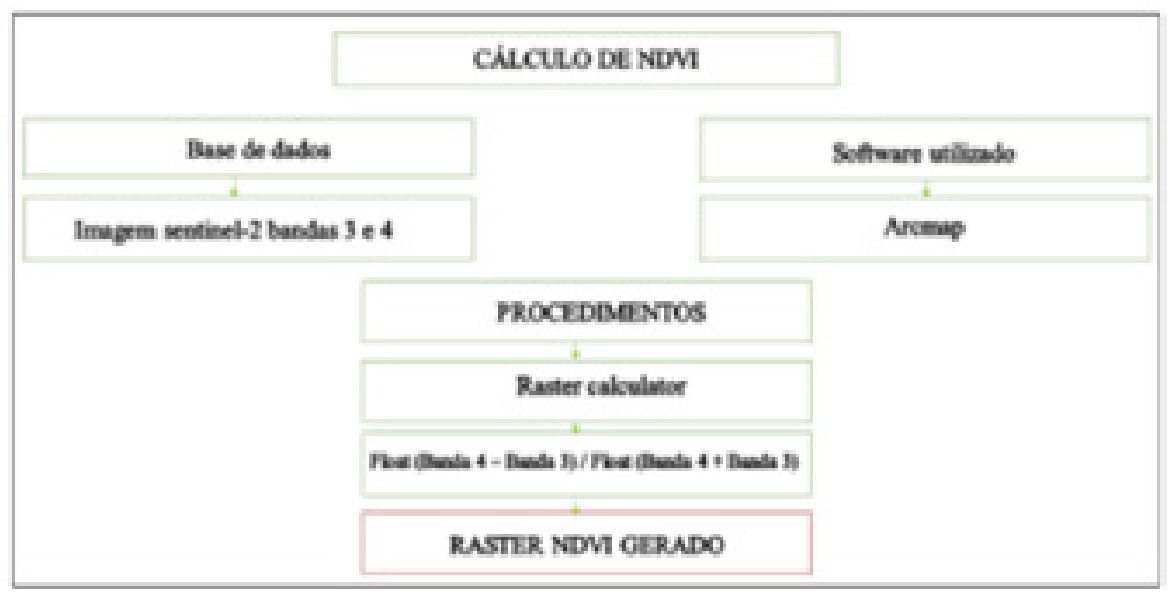

Fonte: Autoria própria (2018).

\section{ETAPA CAMPO}

A etapa de campo ocorreu no dia 13 de outubro de 2018 pela manhã. Durante a visita in loco (Figura 4), foram inspecionados os pontos de acessos e controles vetorizados na fase de pré-campo, constatando, assim, os principais problemas ambientais na microbacia, assim como as classes de uso e ocupação do solo da microbacia do rio Guajiru. Ao todo, foram vistos terrenos do tipo: planícies de inundação, fragmentos de matas nativas, pastagem, drenagem e solo exposto. Além disso, foram vistas plantações de hortaliças e deposição clandestino de resíduos sólidos. 
Figura 4: a) Início da área de estudo na rodovia RN-064 no município de Ceará-Mirim-RN, com o seguinte par de coordenadas geográficas: LAT $05^{\circ} 41,578^{\prime}$ S/ LON 35²7,940’W. b) Assentamento Sebastião nas proximidades da lagoa utilizada pelos moradores, com o seguinte par de coordenadas geográficas: LAT $05^{\circ} 43,443^{\prime} \mathrm{S} / \mathrm{LON} 35^{\circ} 28,951^{\prime} \mathrm{W}$.

a

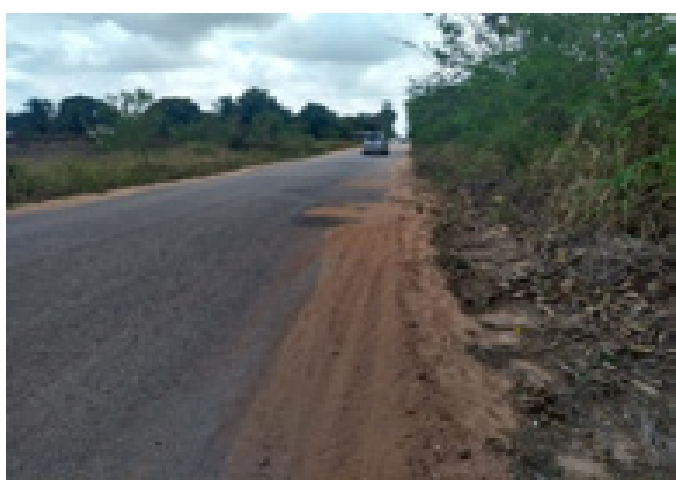

b

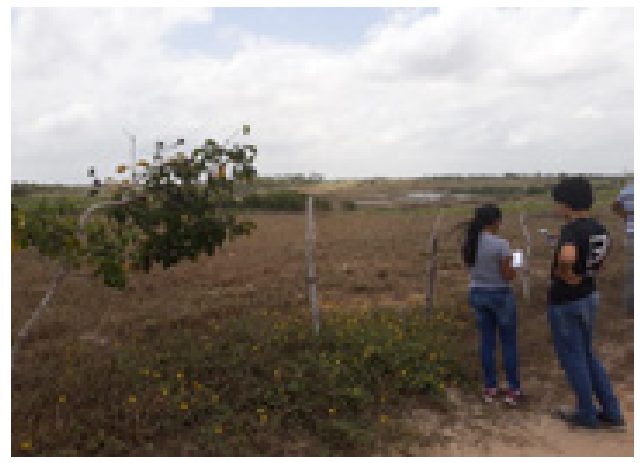

Fonte: Autoria própria (2018).

\section{ETAPA DE PÓS-CAMPO}

Durante a confecção do mapa de uso e cobertura do solo, utilizou-se o algoritmo NDVI nas imagens Sentinel-2 (Figura 5) com a finalidade de se obter informações sobre a vegetação existente na área de estudo. Com os dados de campo, foi possível constatar as seguintes classes de uso e ocupação do solo: drenagem, solos expostos, concentração urbana, fragmentos de mata, pastagem e planícies de inundação.

Figura 5: Raster resultante da utilização do algoritmo NDVI. Vale ressaltar que os valores de NDVI indicam classes de uso e ocupação do solo.
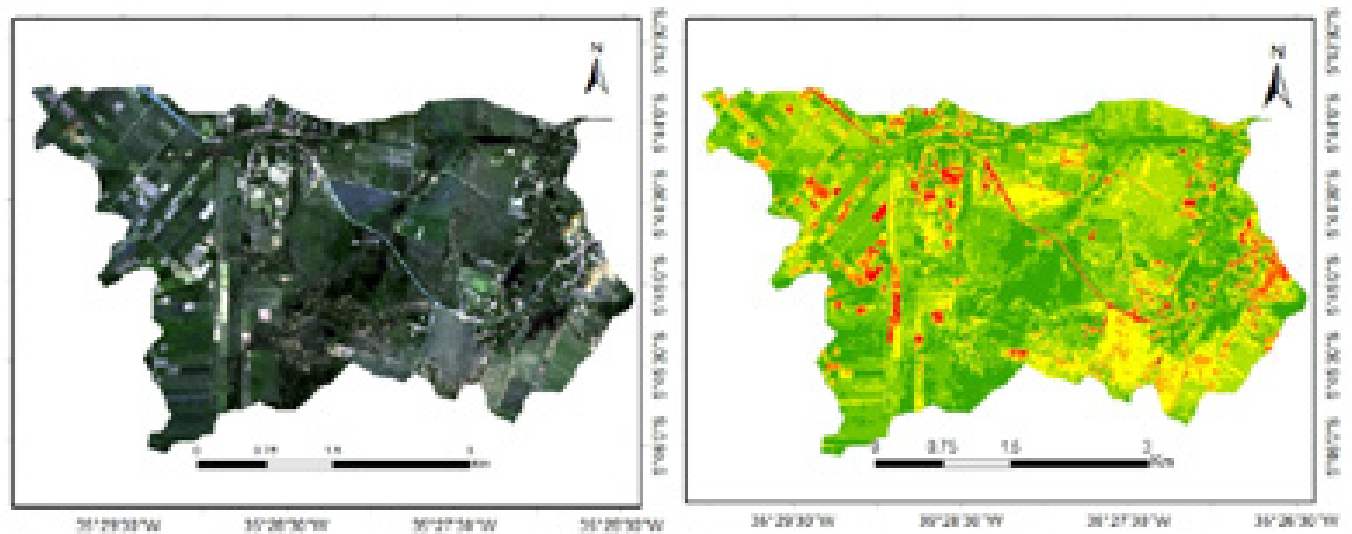

Compesçso colorida da imagem Sentinel:2

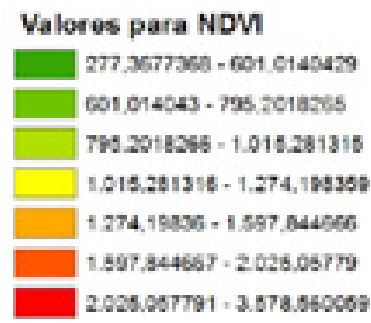

Fonte: Autoria própria (2018). 
Após a escolha das classes com base no NDVI e a imagem Sentinel em sua composição colorida foi possível mapear as classes distintas e calcular o percentual de cada uma com relação a área de estudo. Permitindo a correta analise das áreas conflituosas e geração do mapa de conflito ambiental na microbacia para daí se propor medidas para a diminuição dos impactos nesta microbacia.

\section{RESULTADOS E DISCUSSÕES}

As sete classes do uso e ocupação do solo foram extraídas através do processamento digital de imagens Sentinel-2 com o algoritmo NDVI em parceria com as observações de campo. A microbacia insere-se, principalmente, em áreas rurais ocupadas por atividades relacionadas a cana-de-açúcar que deram lugar, posteriormente, às atividades agropastoris, com a criação de gado extensivo e agricultura de subsistência, destacando-se as culturas de milho, feijão, mandioca e hortaliças. 0 avanço dessas atividades constituiu, ao longo do tempo, um problema ambiental ocasionado, principalmente, pelo desmatamento da mata nativa sem nenhum tipo de manejo florestal, quase total da região.

A interferência antrópica modificou a paisagem da microbacia, provocando a diminuição de sua cobertura vegetal nativa. Os registros fotográficos (Figura 6) evidenciam os aspectos do uso e ocupação do solo na microbacia evidenciados durante a etapa de campo.

Figura 6: As sete classes de uso e ocupação do solo observados durante a visita técnica na MHRG.
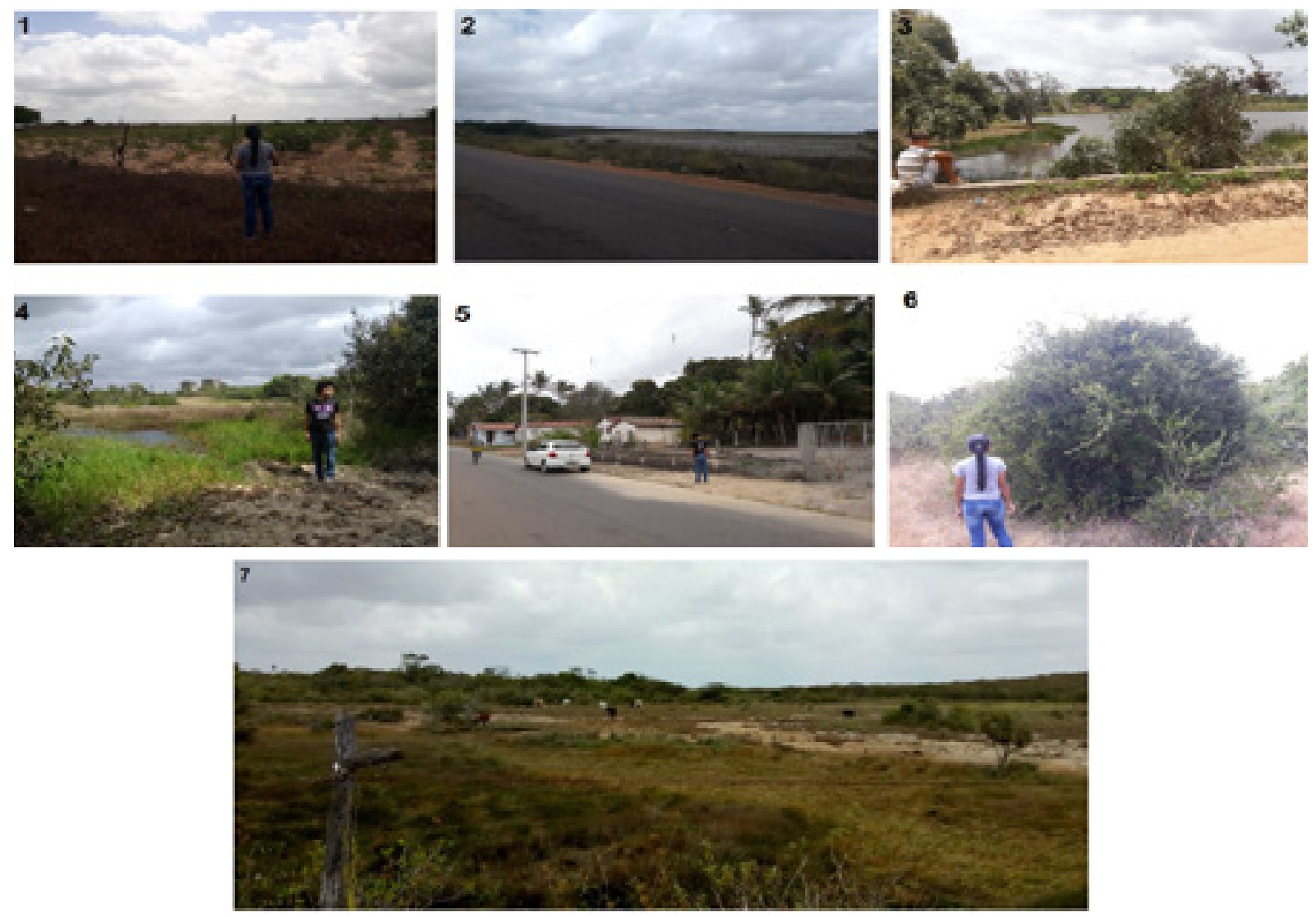

Fonte: Autoria própria (2018). 
A classe 1 apresenta os campos antropizados do lado direito algumas plantações de mandioca nas proximidades do distrito de Canto da Moça no município de lelmo Marinho com as coordenadas. A classe 2corresponde ao início da área sobre a RN-064 em Ceará Mirim, do lado direito apresentando algumas áreas com o solo completamente exposto sem nenhum tipo de atividade.

A classe 3 representa a um corpo hídrico, conhecido por "Lagoinha" pelos moradores do distrito de Riacho do Meio. Na classe4, presencia-se a planície de inundação, formando regiões encharcadas devido ao relevo plano que favorece o acúmulo de água. Na classe 5, no distrito Canto da Moça, há ocupações irregulares, as quais canalizam do rio e promovem cultivos em locais inadequados.

A classe 6 é representada por fragmentos de matas nativas (Caatinga mais Mata Atlântica) e vegetação rasteira conhecida como uma zona de tensão ecológica, pois consta de um contato entre dois biomas. Já a classe 7, nas adjacências daFazenda Tamuatá, há pasto e rio seco. Conforme os resultados obtidos pela análise do uso e ocupação do solo in loco, foi comprovado que a maior parte da área de estudo encontra-se antropizada devido às atividades que ocorrem de natureza agropecuárias (Tabela 1).

Tabela 1: Áreas totais (ha) e porcentagens (\%) relativas às classes de uso e ocupação do solo na microbacia do Rio Guajiru.

Classes

\begin{tabular}{l}
\hline \\
\hline 2 \\
\hline 3 \\
\hline
\end{tabular}

LAT $05^{\circ} 43,930^{\prime} \mathrm{S}$

Coordenadas

geográficas
Uso e ocupação do solo

Área (ha)

Área (\%)
10,37

8,28
13,22
4

LAT $05^{\circ} 4,01^{\prime} \mathrm{S}$
$\operatorname{LOG} 35^{\circ} 26,953^{\prime} \mathrm{W}$

LON $35^{\circ} 28,4447^{\prime} \mathrm{W}$

\section{Campos} antropizados

Solo exposto

$2.842,585$

$2.230,361$

Corpos d'água

Planície de

inundação

Concentração

urbana

$7.571,766$
35,23
LAT $05^{\circ} 43,114^{\prime} \mathrm{S}$

LOG $35^{\circ} 28,073^{\prime} \mathrm{W}$
5

LOG $35^{\circ} 28,420^{\prime} \mathrm{W}$

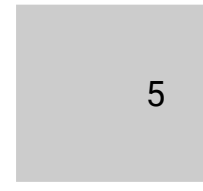

6

LAT $05^{\circ} 43,596^{\prime} \mathrm{S}$

LOG $35^{\circ} 28,278^{\prime} \mathrm{W}$
Fragmento de mata

$1.884,537$

8,76 . 
Conforme os dados apresentados na tabela 1 sobre o percentual de cada classe de uso e ocupação com relação à área total, foi constatado que os campos antropizados ocupam maior parte da área de estudo com 35,23\%. Em geral, esses campos antropizados se encontram ocupados com algum tipo de plantação entre elas mandioca e feijão, ou até mesmo sem nenhum tipo de atividade representando apenas solos expostos ocasionados pelo desmatamento. As pastagens ocupam 18,88\% da área devido a atividade agropastoril que é muito forte. Os solos expostos ocupam $13,22 \%$ da área em seguida dos corpos d'água com apenas 10,37\%. A planície de inundação representa $8,28 \%$ da área total. Porém, se encontra sobre áreas de pastagens seguindo dos fragmentos de mata com $8,78 \%$ da área. Já a concentração urbana se encontra com 5,28 \% da área o que está relacionado com o crescimento dos assentamentos e comunidades na área de estudo.

Os registros fotográficos a seguir (Figura 7) apresentam os principais conflitos ambientais recorrentes na área de estudo que tem contribuído para o aumento da degradação ambiental como as ocupações irregulares no distrito de Canto de Moça localizado no município de lelmo Marinho sobre o vale da microbacia. Um dos problemas identificado neste local foi à retirada da mata ciliar para cultivo de mandioca, banana e outros tipos de hortaliças $(\mathrm{PI})$ que provocou o assoreamento dos canais que passam no distrito. Além disso, a deposição de resíduos sólidos inadequados próximos dos distritos urbanos configura-se na poluição da microbacia supracitada.

Figura 7: Conflitos de uso do solo na microbacia do Rio Guajiru utilizando imagem Sentinel-2 (R4G3B2) e registros fotográficos obtidos durante etapa de campo.

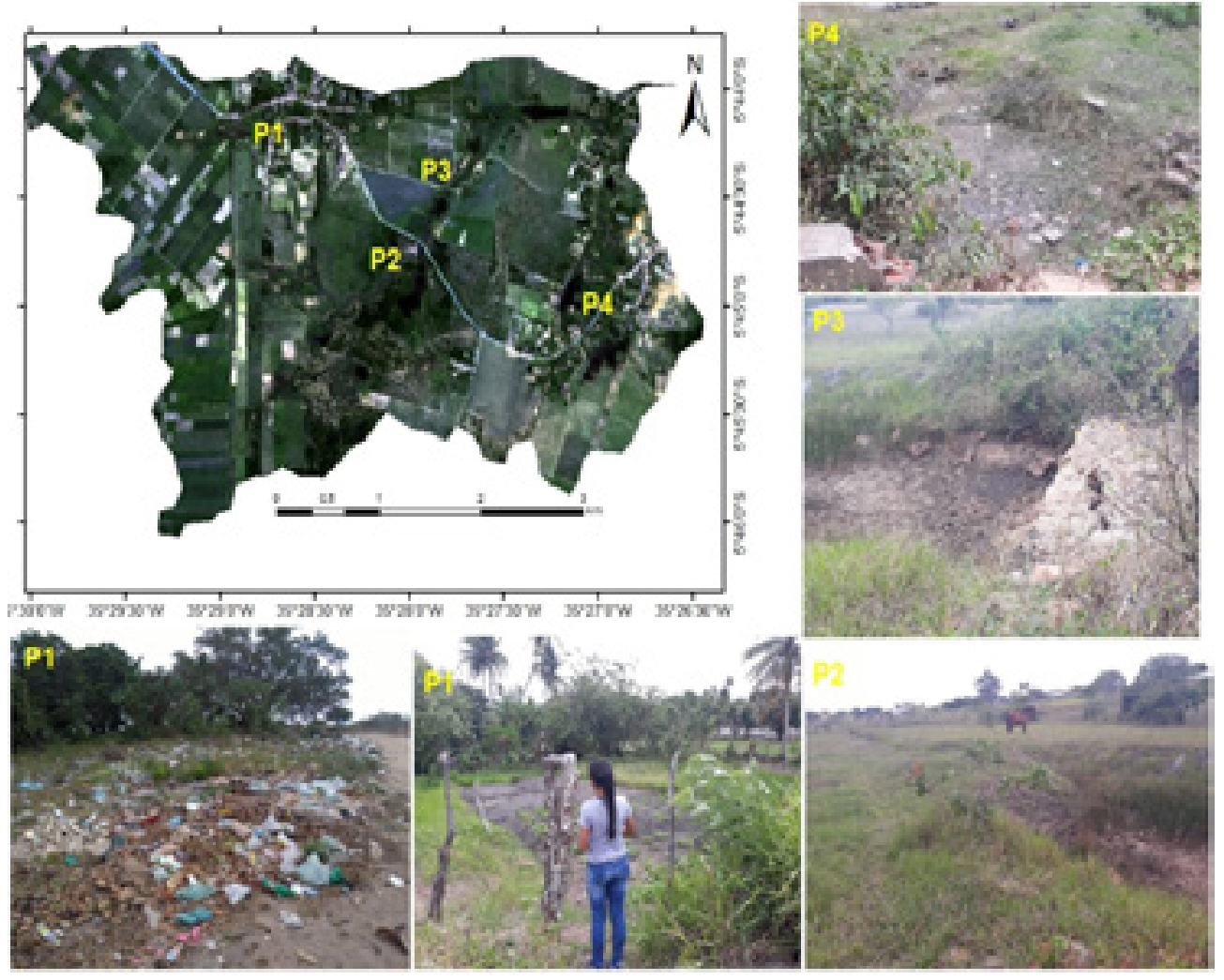

Fonte: Autoria própria (2018). 
Próximo a Fazenda São Pedro II (P2 e P3), os pastos encontram-se com pouca cobertura vegetal, além disso, a mata ciliar próxima do curso d'água foi completamente retirada. 0 ponto (P4) representa também um dos maiores problemas na área de estudo que é retirada da mata ciliar próximos de cursos d'água principalmente devido a prática agropastoril próximo a comunidade de Riacho do meio. Dessa forma, com base nos resultados do NDVI e atividades de campo, foi possível observar que a vegetação nativa nas nascentes dos cursos d'água de primeira e segunda ordem e no restante da área física da microbacia se encontra totalmente comprometida devido ao desmatamento para a atividade agropastoril que se intensifica na região. 0 mapa de uso e ocupação da microbacia (Figura 8) confirma esta análise.

Figura 8: Mapa de uso e ocupação do solo na microbacia do rio Guajiru resultante das análises do processamento digital de imagem Sentinel-2.

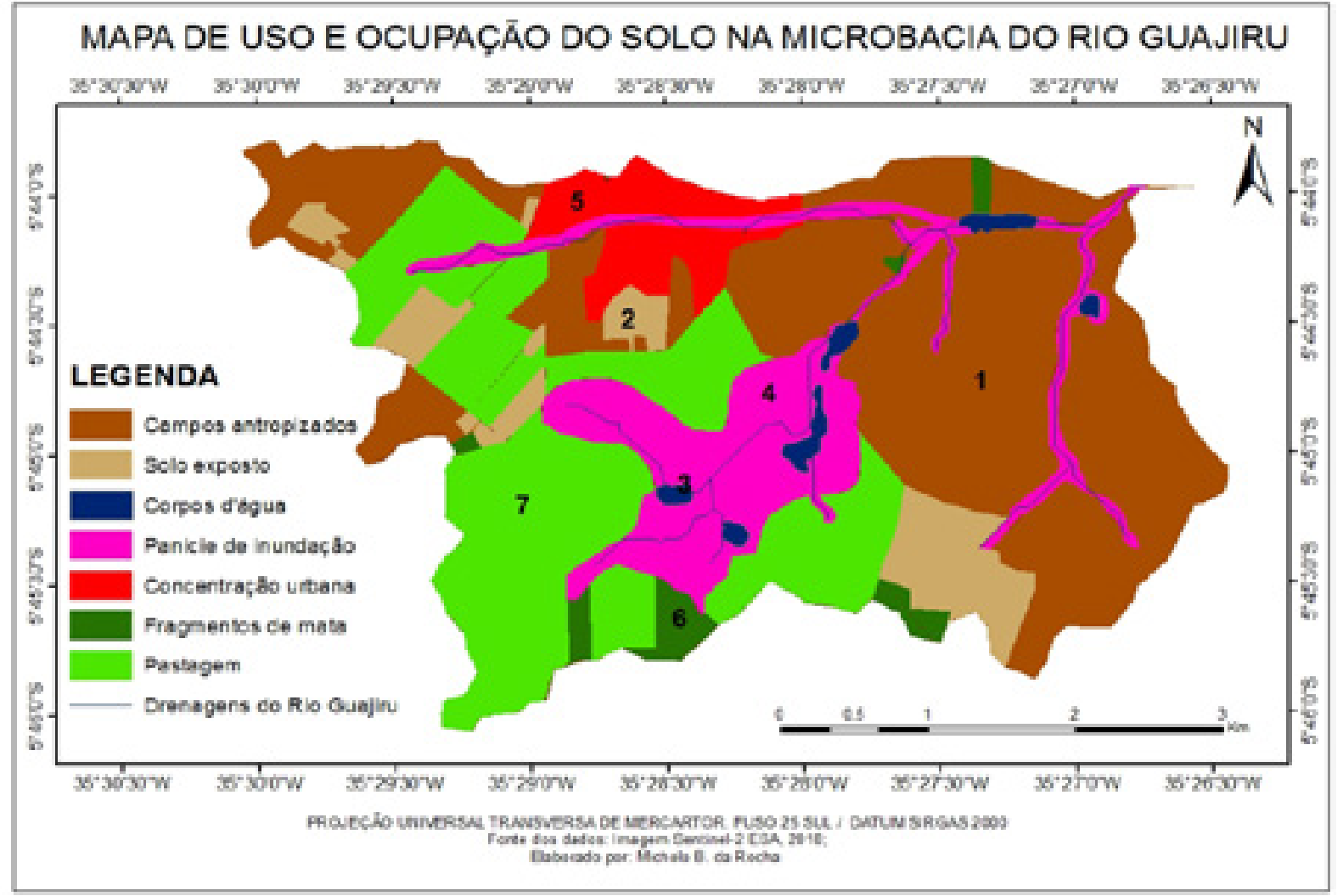

Fonte: Autoria própria (2018)

A figura 8 apresenta as classes de uso e ocupação do solo na microbacia do Rio Guajiru, onde foi observado o predomínio das pastagens e os campos antropizados na área. Sendo assim, a partir do emprego das ferramentas de geoprocessamento e o sensoriamento remoto foi possível realizar uma leitura do geoambiente estudado e suas condições atuais. 


\section{CONSIDERAÇÕES FINAIS}

Por meio do software ArcGIS versão 10.5.foi realizado o levantamento e o mapeamento das principais áreas impactadas a microbacia do Rio Guajiru evidenciando os atuais conflitos ambientais gerados pela interferência antrópica nas proximidades dos cursos d'água. Neste sentido, com base no mapa de uso e ocupação do solo na microbacia foi possível constatar que os campos antropizados ocupam $35,23 \%$ e as pastagens $18,88 \%$ ou seja, maior parte da microbacia do Rio Guajiru se encontra entronizada.

Em geral, esses campos antropizados se encontram ocupados com algum tipo de plantação entre elas mandioca e feijão, ou até mesmo sem nenhum tipo de atividade representando apenas solos expostos. As pastagens por sua vez se encontram cada vez mais em maior parte principalmente em áreas encharcadas. Vale ressaltar que o mais agravante problema constatado nesta pesquisa foi o desmatamento que a microbacia vem sofrendo nos últimos anos devido a expansão das atividades agropastoris, no entanto, conforme a legislação ambiental todo corpo d'água em áreas rurais deve ser conservado, se tratando das áreas de preservação permanente deve ser mantido uma faixa de cobertura vegetal conservada com a finalidade de proteger os recursos hídricos.

Sendo assim, se faz necessário o fortalecimento dos estudos nessa área já que se trata de um dos afluentes de uma bacia hidrográfica utilizada para abastecimento humano. Assim como a implantação de políticas públicas voltadas para a recuperação ambiental das nascentes do Rio Guajiru.

\section{REFERÊNCIAS}

1. CHAGAS, L.M. F.das. Caracterização do Uso e Ocupação da Bacia do RioDoce/RN. 1997. 105 f. Monografia (Graduação em Geografia) - Universidade Federal do Rio Grande do Norte, Natal, 1997. COSTA, F.R. da.; SOUZA, R.F. de.; SILVA, S.M.P. da. Análise comparativa de metodologias aplicadas à delimitação da bacia hidrográfica do rio doce -RN. Soc. \& Nat., Uberlândia, v 28, n. 3, p. 429-442, dez. 2016.

2. FAUSTINO, A.B.; RAMOS, F. F.; SILVA, S.M.P. da. Dinâmica temporal do uso e cobertura do solo na Bacia Hidrográfica do Rio Doce (RN) com base em Sensoriamento Remoto e SIG: uma contribuição aos estudos ambientais. Sociedade e Território, Natal, v. 26, n. 2, p. 18 - 30, dez. 2014.

3. LIMA, M. das G. Caracterização da Bacia do Rio Doce, Natal/RN. 2005. 87 f. Monografia (Graduação em Geografia) - Universidade Federal do Rio Grande do Norte, Natal, 2005.

4. MARRAFA, V. de O. Análise e discussão sobre a possível criação de uma unidade de conservação na bacia hidrográfica do Rio Doce. 2017. 56 f. Monografia (Graduação em engenharia ambiental) Universidade Federal do Rio Grande do Norte, centro de tecnologia. Natal, 2017.

5. MOREIRA, M. A. Fundamentos do sensoriamento remoto e metodologias de aplicação.4. Ed. Viçosa, MG: ED. UFV 2011, 422p.

6. MOREIRA, F. D. Geotecnologia aplicada à sub-bacia hidrográfica do Rio Piauitinga e suas relações ambientais. 2008. 101 f. Dissertação (mestrado em geografia) - Universidade Federal de 
Sergipe, São Cristóvão, 2008.

7. PALERMO, Marco Antonio. Gerenciamento ambiental integrado. Annablume; São Paulo 2006.

8. PAISE, A. e (Orgs). Conservação da biodiversidade com SIG. São Paulo: oficina de textos, 2012.

9. PIRES, J. S.R., SANTOS, J.E., DEL PRETTE, M. E. A utilização do conceito de bacia hidrográfica para a conservação dos recursos naturais. In: SCHIAVETTI, A. CAMARGO, A. F.M. Conceitos de bacias hidrográficas: Teorias e aplicações. Ilhéus: Editus, 2008. p.17-35.

10. PINA, M. de F. de. SANTOS, S. M. Conceitos básicos de Sistemas de Informação Geográfica e Cartografia aplicada à saúde. 20. ed. OPAS - Brasília, 2000.

11. BOTELHO, R. G. M,. SILVA, A. S. da. (Orgs.)A. C. GUERRA, A. J. T. Bacia hidrográfica e qualidade ambiental. In: BOTELHO, R. G. M,. SILVA, A. S. da. (Orgs.).Reflexões sobre a geografia física no Brasil. Rio de Janeiro: Bertrand, 2004.p.159-17 